\title{
EL PROGRAMA “SALVADOS” EN EL SISTEMA AUDIOVISUAL ESPAÑOL: ELEMENTO HERÉTICO O LA EXCEPCIÓN QUE CONFIRMA LA REGLA
}

\section{"SALVADOS” WITHIN THE CONTEXT OF THE SPANISH AUDIOVISUAL MEDIA SYSTEM: HERETICAL ELEMENT OR THE EXCEPTION THAT CONFIRMS THE RULE}

\author{
Rosalba Mancinas-Chávez \\ Universidad de Sevilla \\ rmancinas@us.es \\ Elizabeth Galán Linares \\ Universidad Pompeu Fabra \\ Universidad de Sevilla \\ eliigl1992@gmail.com
}

Resumen: Partiendo del concepto 'herético' que recoge Ramón Reig (1995) de los sociólogos Peter Berger y Thomas Luckmann (1991) hacemos un análisis del programa "Salvados", que se emite en la cadena española de televisión La Sexta y lo hacemos con el fin de averiguar si representa una alternativa de comunicación o es la excepción que confirma la regla dentro del panorama audiovisual español.

Tras el proceso de investigación, podemos afirmar que, si bien es cierto que ofrece una comunicación diferente, encaja dentro de la Estructura de la Información sin dañarla. Por lo tanto, no podemos concebirlo como elemento herético, se trata más bien de "la excepción que confirma la regla" porque el conjunto de sus programas muestra una perspectiva distinta, frente a la oferta homogénea de los demás espacios televisivos. "Salvados" realiza un periodismo transgresor puntualmente, que molesta a la estructura de poder.

Palabras clave: Salvados, Sistema audiovisual español, Economía política de la comunicación, Jordi Évole, La Sexta, Atresmedia.
Abstract: Based on the heretical concept that Ramón Reig (1995) picks up from Peter Berger and Thomas Luckmann (1991), we analyze "Salvados", a program broadcast on the Spanish television station La Sexta. We aim to find out if this program represents an alternative to the traditional media or if it is the exception that confirms the rule in the audiovisual media system in Spain. After the process of research, we can affirm that, although the program offers a different kind of information, it fits inside the information structure without damaging it. Therefore, it is not a type of alternative communication, it is "the exception that confirms the rule" because it presents a different perspective compared to the homogeneous offerings of other TV programs. "Salvados" only occasionally offers a kind of transgressive journalism that disturbs the power structure.

Key words: Salvados, audiovisual media system in Spain, political economy of communication, Jordi Évole, La Sexta, Atresmedia. 


\section{Introducción}

Ramón Reig (1995) recoge de los sociólogos Peter Berger y Thomas Luckman (1991) el concepto herético para referirse a los elementos sociales que cuestionan el sistema establecido. A partir de ese concepto, en este artículo pretendemos analizar el programa de televisión "Salvados", que conduce el periodista Jordi Évole y se emite en España en la cadena La Sexta. El interés es indagar si este programa representa una esperanza de libertad de expresión al plantear un periodismo comprometido, que saca a la luz temas de fuerte calado social donde se muestran claros conflictos de intereses o si es un programa con apariencia de elemento herético pero es parte del sistema.

Para conseguirlo, primero hacemos un breve repaso a la estructura de propiedad de La Sexta dentro del contexto del grupo Atresmedia. Luego desglosamos algunos programas que hemos seleccionado como de especial relevancia por mostrar claros indicios de cuestionamiento del sistema. También hemos recurrido a entrevistas con expertos (Aurora Labio y Ramón Reig) para indagar en aquellas cuestiones que, por ser demasiado recientes, no están escritas.

El punto de partida es la inquietud por averiguar qué lugar ocupa "Salvados" dentro de la estructura empresarial de Atresmedia, donde conviven las cadenas de televisión Antena 3, de tendencia conservadora, y La Sexta, de tendencia progresista, entre otros medios de comunicación y otras empresas de diferentes sectores. Nuestra investigación está orientada al descubrimiento de los distintos intereses políticos y económicos bajo los que pudiera trabajar el equipo de "Salvados", encabezado por Jordi Évole. Partimos del supuesto de que el periodismo y los periodistas pueden estar condicionados por las empresas de sectores distintos al de la información que conecten con La Sexta a través del accionariado o del Consejo de Administración (Reig, 2011; Serrano, 2010). Es decir, las grandes empresas pueden utilizar sus participaciones en los medios para conseguir a través del control del mensaje una buena imagen. Por otro lado, los partidos políticos también influyen en la rutina periodística. En este caso, el mecanismo consiste en una cadena de favores, por ejemplo, publicidad institucional a cambio de buena prensa (Reig, 2011).

En este panorama mediático, "Salvados" se muestra como un programa diferente que presenta una oferta de capítulos muy variados y de carácter innovador y crítico. La personalidad del presentador distingue sus emisiones por la naturalidad y soltura con la que realiza las entrevistas, dejando la sensación a la opinión pública de que el equipo de Jordi Évole realiza su labor periodística con independencia.

\section{Metodología}

Abordamos este trabajo desde la perspectiva de la Economía Política de la Comunicación, que entendemos como la ciencia que se ocupa de averiguar las relaciones sociales mediante las cuales se lleva a cabo el proceso de producción, distribución y consumo de bienes procedentes de medios de comunicación. Como una visión que se centra en el estudio de la naturaleza económica de los medios de comunicación y los sistemas comunicativos a los que pertenece y su relación con la estructura social más amplia. En concreto, revisa la propiedad, la financiación y las políticas públicas por las que se rigen los medios de comunicación para comprobar cómo influyen en los contenidos y el comportamiento de los medios (Gómez García y Sánchez Ruiz, 2013). 
Usamos como herramienta metodológica el enfoque estructural (Reig, 2011), que recomienda entender la comunicación como un sistema compuesto por una serie de elementos articulados, organizados e interconectados, de tal forma que si alguno de éstos sufre modificaciones el conjunto se verá afectado. El sistema propiamente dicho es un concepto más amplio que abarca la estructura de forma más natural.

El enfoque estructural se deriva de la Estructura de la Información, rama de la Economía Política de la Comunicación que estudia las relaciones que se establecen entre los elementos informativos, políticos y económicos; su influencia en los mensajes y, por lo tanto, en la sociedad. Concibe como elementos informativos los medios de comunicación, la audiencia, los periodistas o los grupos de comunicación en sí. Por otro lado, los medios de comunicación también se consideran elementos económicos, junto con las corporaciones económicas propiamente dichas (Reig, 2011).

Concretamente, investiga cómo se articulan las empresas de comunicación y otras de múltiples sectores, interconectadas con el mundo económico, político y financiero. También se centra en la repercusión de estos condicionantes en los medios de comunicación, incidiendo así en el mensaje emitido. Por lo tanto, el estudio desde el enfoque estructural aporta una visión de conjunto y es importante para apreciar cómo se produce la codificación de la información según los intereses que articulan el proceso y dependiendo de las distintas interconexiones y cómo influyen en la opinión pública.

En concreto, en la investigación lanzamos el interrogante: ¿ “Salvados" se corresponde con la definición de herético o se trata más bien de la excepción que confirma la regla? Nos proponemos analizar si "Salvados" es comunicación alternativa o simplemente una fórmula diferente de hacer periodismo dentro de una estructura que lo soporta como el elemento que justifica su funcionamiento. Para solucionar esta cuestión, primero hacemos una revisión a los orígenes empresariales de La Sexta, lo situamos en el contexto de Atresmedia y averiguamos con qué elementos estructurales conecta. Complementamos esta visión con un análisis de contenidos para el cual hemos elegido el capítulo "Oligopoly: el juego de la energía", una de las emisiones más polémicas porque difundió el sistema mediante el cual varía el precio de la luz. Utilizamos el análisis de otros capítulos para aportar argumentos.

Recurrimos a fuentes documentales en Internet y a fuentes orales por ser un tema novedoso en el que no encontramos suficientes fuentes bibliográficas.

\section{Resultados}

El día 23 de febrero de 2014, el equipo de "Salvados" emitió el documental de ficción titulado "Operación Palace", que obtuvo gran repercusión en los medios de comunicación y redes sociales.

El mockumentaries que proponía una versión del "23F" contó con la colaboración de personajes tan importantes como Iñaki Gabilondo o Fernado Ónega. La participación de líderes de opinión de reconocido prestigio en este programa tan arriesgado y polémico demuestra el prestigio y la confianza que ha ido ganando Jordi Évole como profesional gracias al programa "Salvados" y a su labor como periodista.

La edición especial titulada "23F" propició gran participación del público durante su emisión mediante Twitter. Algunos medios de comunicación de referencia como Abc se hicieron eco de la emisión y el éxito de audiencia. Entre la población hubo reaccio- 
nes de todo tipo, aunque la mayoría cayó en la enérgica trampa que había preparado el equipo de Jordi Évole, demostrando la credibilidad que se le concede a "Salvados" y que suma un argumento más para afirmar que Jordi Évole se ha convertido en un personaje trascendental en el contexto del periodismo español.

Al final del programa, se desveló que todo era un montaje y Jordi Évole se justificaba así:

Sé que en este momento habrá espectadores que estarán contentos con lo que han visto porque se lo han pasado bien y otros que se sentirán engañados y me querrán matar. A los primeros les querría decir que gracias por jugar con nosotros $y$ a los segundos, que la próxima vez lo intentaremos hacer mejor. Al menos nosotros hemos reconocido que era mentira lo que hemos contado y seguramente ha habido otras veces que era mentira lo que les han contado y nadie se los ha dicho (Salvados, 2014b).

Como vemos, aquí explica en qué consistía el experimento al que sometió a todo el país aquella noche. Teniendo en cuenta que concebimos la realidad mediante la telepantalla, Jordi Évole quiso que la gente reflexionara y se preguntara cuánta información de la que se emite en televisión es falsa. Con ello, pretendía activar la conciencia crítica ante los medios de comunicación.

Otra de las intenciones del productor y periodista era "comprobar si somos suficientemente adultos como para hablar de temas considerados sagrados como la Monarquía o la Transición", según declaró en la explicación del falso documental.

El derecho de los ciudadanos a una información veraz viene recogido en la Constitución Española y en la Europea y es necesario protegerlo para salvaguardar la democracia. De ahí, que debamos preocuparnos por el tipo de información que emiten los medios (Urías, 2003).

El doctor y profesor Enrique Bonete (1995: 209) afirma en su libro Éticas de la Información y Deontologías del Periodismo, que, si aplicamos la visión profesional a la función de informar, el periodista debería crear el mejor producto informativo posible. Debe trabajar con responsabilidad profesional y ponerse al servicio de la Información como institución social.

Los periodistas no deben ceder ante los intereses enmascarados de la cúpula interna del medio de comunicación. "No es lícito, en una democracia, informar de cualquier manera, informar de cualquier modo" (Bonete, 1995: 61).

"Salvados" se emite en la cadena generalista La Sexta, que tuvo su origen en 2006 por iniciativa del Grupo Audiovisual de Medios de Producción (GAMP) y el gigante mexicano Televisa. Con el Decreto Ley de las Fusiones de 2009, se permitió la unión de La Sexta con Antena 3, formando el grupo Atresmedia, presidido por José Manuel Lara. Dentro del grupo, La Sexta convive con otros medios de comunicación como Onda Cero, Neox o Gol TV. Atresmedia tiene acciones en empresas de todo tipo, dentro de la dinámica habitual de diversificación, y su accionariado conecta con empresas de todo el mundo.

\subsection{Atresmedia, La Sexta, "Salvados" y Jordi Évole}

En España, la crisis de mercado en el ámbito de la comunicación ha propiciado la concentración mediática en el sector audiovisual dando como resultado el reparto de las principales cadenas en dos grupos mediáticos: Mediaset España y Atresmedia (Serrano, 2010). Con la llegada de la TDT en 2010 se aumentó la cantidad de ca- 
denas de televisión de acceso abierto, con la finalidad de propiciar la diversidad de puntos de vista. En la práctica, las grandes cadenas de televisión pertenecen a dos grupos: Mediaset España que surge con la unión de Telecinco y Cuatro, y Atresmedia que nace con la unión de Antena 3 y La Sexta (Reig, 2011).

\subsubsection{Atresmedia}

La Sexta y Antena 3 pudieron fusionarse en el grupo Atresmedia según el Real Decreto Ley de fusiones del año 2009, resultando una oferta muy completa y diversificada en todas las posibilidades multimedia. Actualmente el conglomerado aglutina a los siguientes medios de comunicación (Labio, 2014):

- Televisión: Antena 3, La Sexta, Neox, Nova y Gol TV.

- Radio: Onda Cero, Europa FM, Melodía FM y Verte.

- Internet: Nubeox (películas, series) y Atresplayer (tv, radio...).

- Publicidad.

Su Consejo de Administración está liderado por José Manuel Lara Bosch como presidente y por Maurizio Carlotti como vicepresidente, junto con Imagina Media Audiovisual S.A., representado por José Miguel Contreras Tejera.

José Manuel Lara explicó a los medios en un primer momento que los informativos de Antena 3 y La Sexta mantendrían una línea editorial independiente y que la redacción de las noticias sería diferenciada entre ambas. Más tarde, sorprendió con unas declaraciones en las que afirmaba que pretendía que La Sexta fuera "una televisión de centroizquierda seria" y "respetuosa con la derecha". Estas declaraciones fueron muy polémicas, ya que se cuestionaba el pluralismo del conglomerado y la independencia con la que iba a trabajar La Sexta.

Su composición accionarial está encabezada por Atresmedia Corporación de Medios de Comunicación, S.A. Planeta de Agostini posee un $41,70 \%$ de las acciones y le siguen UFA con un $19,17 \%$, Imagina con un $10,20 \%$ y Autocartera con un $0,51 \%$. Del resto de acciones, un $28,42 \%$, no se especifican los propietarios.

Por lo tanto, Imagina Media Audiovisual, el holding español fruto de la fusión de Mediapro y Globomedia, ahora es un integrante más del accionariado del grupo Atresmedia desde su fusión con Antena 3 en 2009. Imagina participa directamente como accionista con un $4,484 \%$ e indirectamente a través de GAMP Audiovisual, S.A., la sociedad de su grupo, con un $5,718 \%$. Por otro lado, La Sexta, la cadena estrella del grupo Imagina, ha adoptado un amplio protagonismo dentro del grupo Atresmedia. Desde que La Sexta se incorporó a Atresmedia Televisión ha alcanzado sus resultados más altos en audiencia, llegando al 5,5\% de cuota de pantalla en diciembre de 2012.

\subsubsection{La Sexta}

La Sexta surgió del antiguo grupo Imagina-Mediapro, un entramado de más de 40 empresas cuya organización y nombres sólo salieron a la luz cuando el juzgado obligó a la corporación a entregar documentación para solicitar el concurso de acreedores. El Grupo Prisa, que siempre ha estado enfrentado con La Sexta por su rivalidad con el canal Cuatro, tuvo acceso a los papeles y desveló la enrevesada galaxia empresarial (Serrano, 2010: 246).

Los orígenes de la cadena se remontan a marzo de 2006 cuando GAMP Audiovisual y Televisa, el conglomerado mexicano que se expande más allá de sus fronteras, 
impulsaron el proyecto de La Sexta. A lo largo de los años, la cadena ha ido cambiando de accionistas desde su creación, pero se siguen manteniendo los principales: GAMP Audiovisual (51,658\%) y Televisa (40,517\%) (Reig, 2011: 141).

La Sexta empezó a emitir el 26 de marzo de 2006, posicionándose, según un estudio de Ricardo Vaca entre 2006 y 2008 (2010: 39), como una televisión generalista, convencional y en abierto, con espacios de todo tipo de géneros: entretenimiento, información, deportes, ficción, divulgativos o culturales, concursos.

En un principio, su programación se caracterizaba en su mayoría por los contenidos televisivos de género deportivo, al que dedicaba un 35,1\% del total. En segundo lugar, la cadena invertía un $28,1 \%$ en contenidos de entretenimiento, seguido de un $15,2 \%$ para los programas de ficción. Los divulgativos o culturales ocupaban un $13,5 \%$ y sólo se empleaba un $6,5 \%$ a los concursos y un $1,6 \%$ a los informativos (Ricardo Vaca, 2010: 42).

Ricardo Vaca (2010: 142) concluyó en su análisis que La Sexta se dirige en un 54\% a un público con una edad inferior a los 45 . Además el perfil de espectador de clase media-media prefiere La Sexta, solo un poco más por encima que los seguidores de la clase alta (Ricardo Vaca, 2010: 152).

Antes de unirse a Atresmedia, los principales accionistas de La Sexta reorganizaron sus posiciones. Televisa entró al accionariado de Imagina con un 14,5\%. Paralelamente traspasó a Imagina todas las acciones que poseía en la cadena, de esta manera Imagina pasa a controlar directa o indirectamente el 92\% de La Sexta, con el resto del poder en manos de Gala Capital (Gómez y Gallo, 2011).

\subsection{3. "Salvados" - Jordi Évole}

Es complicado llevar a cabo un periodismo digno en España porque los periodistas están sujetos a unos condicionantes económicos y políticos que inciden en su desarrollo, pero es cierto que hay profesionales comprometidos que lo intentan todos los días (Labio, 2014).

"Salvados" prepara todas las semanas reportajes de actualidad que tratan los temas más relevantes con un peculiar estilo humorístico y provocativo. Para Aurora Labio (2014), se ajusta a los estándares de calidad porque realiza reportajes de investigación muy buenos, como cuando devolvió el tema del metro de Valencia a la opinión pública, y entrevistas muy interesantes, como la de José Mújica, presidente de Uruguay.

La profesora de la Universidad de Sevilla afirma que el programa ha conseguido combinar el éxito televisivo con el análisis de temas interesantes en un tono distendido. De momento, no se ha visto condicionado de manera directa aunque José Manuel Lara lo pretendiese después de la fusión con Antena 3. Por el contrario, el programa se ha mantenido en la parrilla con su estilo propio como seña de identidad de la cadena La Sexta. La razón está en que, para la cúpula de Atresmedia, "Salvados" no deja de ser una estrategia empresarial para asegurarse un sector determinado de la audiencia, ya que satisface a un público target de tendencia progresista. Además, el programa no da problemas en el conglomerado para convivir con medios de ideología muy diferente, como La Razón (Labio, 2014).

Jordi Évole presenta, produce y dirige el programa, junto con la productora El Terrat, la productora de televisión, teatro e internet de Andreu Buenafuente. Forman un buen equipo porque Jordi Évole se caracteriza por el toque de humor e ironía que le da a sus trabajos y El Terrat plantea sus producciones con provocación y singularidad. 
El carácter personalista de "Salvados" hace que hablar del programa nos lleve a hablar de la personalidad de Jordi Évole y su evolución como periodista. Su carrera se disparó en el año 2000, cuando se convirtió en el guionista de "La Cosa Nostra", el programa que presentaba Andreu Buenafuente en TV3. También fue colaborador, subdirector y guionista del programa de "La Sexta Buenafuente" e interpretó el personaje "El Follonero", un supuesto crítico espontáneo del programa que se sentaba entre el público.

Jordi Évole recorrió todo este camino antes de presentar su propio programa. "Salvados" se estrenó el 24 de febrero de 2008 como una serie de programas especiales, pero con el inicio de la segunda temporada, el 19 de octubre de 2008, abandonó su carácter temático y pasó a emitirse semanalmente. En total ya van 12 temporadas, con un gran abanico de temas de actualidad.

"El Follonero" se convirtió en uno de los periodistas más prestigiosos del país por la labor de denuncia que cumple con su programa y el compromiso social que asume al poner en contacto a los ciudadanos con las instituciones y políticos.

Aurora Labio (2014) opina que su imagen juega a su favor, ya que no lo vemos como un periodista sesudo de la vieja guardia ni posicionado políticamente, aunque sí ideológicamente. Supone otra forma de hacer periodismo basada en la figura de un buen entrevistador que sabe mantenerse en un segundo plano para que el público se centre en el entrevistado. También es muy importante que cuente siempre con una buena base documental detrás, como la que almacena en su tablet. Ahí guarda la prueba irrefutable sobre la que se fundamentan sus preguntas, toda una estrategia dialéctica y retórica, con la que el entrevistado no puede negar la información y no tiene más salida que contestar.

Jordi Évole se refirió a sí mismo explicando la fórmula que hace su programa especial: "A mí el traje este de cómico humorista me venía bastante grande y el de periodista más estricto igual también, por eso no soy ninguna de las dos cosas. He hecho una mezcla de lo poquito que sé de cada cosa y lo he sumado y es lo que puedo hacer en "Salvados" y lo hago muy cómodo" (Salvados, 2013).

Según sus declaraciones, al reconocido periodista no le preocupan las orientaciones políticas que pueda tornar el programa:

Yo voy a mi bola, no tengo una necesidad de quedar bien con nadie del PSOE. De hecho, me consta que hay mucha gente del PSOE que muy bien no nos mira [...]. Yo creo que la evolución del programa "Salvados" hoy en día ha conseguido llegar a mucha gente de derechas, aunque históricamente no se vinculen con la ideología de la cadena, y no tengan problemas para verlo" (Salvados, 2013).

En palabras de Jordi Évole, "Salvados" es un programa provocador: "Salvados no contribuye a la tristeza nacional, al menos no siempre. Contribuye más al cabreo". En opinión de Wyoming, presentador de "El Intermedio" y compañero de Jordi Évole en La Sexta, "de alguna forma 'Salvados' le dice a la gente que no está loca, que eso que ven, es verdad" (Salvados, 2013).

Los personajes más polémicos del país temen someterse al examen del equipo de Jordi Évole porque saben que sus preguntas irán hasta el fondo de la cuestión y eso puede ir en contra de sus planes, así como dañar su imagen o desvelar sus secretos. Al periodismo como tal, le corresponde vigilar el poder público y privado, político y económico para que no actúen de forma ilícita ni contra el bien común de la sociedad. 


\section{2. "Oligopoly, el juego de la energía"}

El 18 de noviembre de 2012, "Salvados" emitió el décimo capítulo de la séptima temporada, titulado "Oligopoly: el juego de la energía". En él se trató una de las principales preocupaciones de los ciudadanos, la factura de la luz. Los consumidores notan como cada año sube sin control, aunque no sean especialistas. Por ello, Jordi Évole investiga en este capítulo de dónde vienen los costes y su continua inflación.

El equipo de "Salvados" viaja hasta la Central Nuclear de Trillo, Guadalajara, para hablar con Carmen Monforte, periodista del diario Cinco Días, y pedirle que les explique cómo funciona la factura de la luz. Afirma que se paga mucho más que hace años debido a que los peajes de acceso, que suponen más de la mitad del recibo de la luz, no dejan de aumentar. De hecho, ha aumentado un $70 \%$ en 6 años sin poner freno al déficit porque el sistema funciona como una hipoteca con intereses y debemos 24 mil millones de euros.

A todo esto se le suman el déficit de tarifa, un préstamo que los ciudadanos le debemos a las eléctricas. No obstante, el sector bancario compró esta deuda, de forma que ellos se convierten en los intermediarios. Así que las industrias eléctricas siguen obteniendo beneficios y el déficit de tarifa tiene un efecto relativo sobre sus cuentas.

Jorge Morales, socio protector de la Fundación Renovables y también empresario de planta de energía solar, explica que las industrias eléctricas han complicado la factura a posta porque "una de las herramientas para eliminar la competencia es la complejidad".

Sólo Iberdrola, Gas Natural Fenosa, Endesa, EDP (Portugal) y E.ON (Alemania) ocupan el $80 \%$ de la generación y cerca del $90 \%$ de la comercialización, de forma que expulsan a la competencia. Por ejemplo, Gaz de France, gigante del gas a nivel internacional, ha anunciado la puesta en venta de sus centrales de gas en España porque no puede competir con las demás españolas.

Por lo tanto, podemos hablar de un oligopolio porque son pocas las empresas que controlan el mercado. Esto puede llevar a prácticas irregulares, como fijar precios. En la Cadena Ser, se informó de una sanción a las industrias eléctricas de 61 millones de euros por pactar precios y ocultar información. No obstante, las industrias facturan 35 mil millones de euros anuales, lo que hace poco significativa la multa.

El precio $\mathrm{KW} / \mathrm{h}$ se fija según los peajes y las subastas diaria y trimestral. En la subasta diaria entran exclusivamente compañías eléctricas mediante un mercado electrónico gestionado por la web omie.es. En ella podemos ver que el precio de la energía que se consume a las 15.00 horas no es el mismo que a las 22.00 horas, pero al consumidor le costará lo mismo en la factura de la luz, pese a los rumores. La electricidad solo le saldrá más barata en ciertas horas a la empresa.

En la web, el precio se va fijando según oferta y demanda en una gráfica. En la mayoría de los casos, los compradores son los mismos que los vendedores. "El pescadero y el pescador son los mismos", ejemplifica Jorge Morales. Las empresas energéticas utilizan esta trama para fijar el precio que les interesa, como subirlo para ganar más dinero o bajarlo para librarse de la competencia. Por lo tanto, volvemos a ver que el mercado de la electricidad es un oligopolio en el que el precio de venta no tiene nada que ver con el coste del producto, como ocurriría en un sistema de libre mercado. Por otro lado, el coste real de la electricidad se niega y no hay transparencia

En la subasta trimestral, participan las industrias eléctricas y los agentes comerciales, como la banca comercial o de inversión. Todos los actores especulan, aunque las 
identidades bancarias no produzcan. De esta manera, los bancos son intermediarios inflacionistas, que estiman un precio, que siempre es superior. Esto supone un cargo adicional y salen ganando.

Jorge Morales recuerda cuando se citó con el asesor del ministro Miguel Sebastián durante el Gobierno socialista para explicarle la insostenibilidad de la situación. El Gobierno se tomó su tiempo y al final del mandato quitó la prima de riesgo. No obstante, esto no es suficiente. La especulación está afectando al colectivo de consumidores vulnerables, que no pueden hacer frente a los precios de un bien tan necesario como es la electricidad. Son los ciudadanos los que están sufriendo la desregulación, por ello, el Gobierno debería entrar en el juego.

El equipo de "Salvados" viaja a la Gasolinera de Majadahonda en Madrid para descubrir si ocurre lo mismo con las petroleras. Allí Jordi Évole habla con Alfredo Hernández, asesor jurídico de estaciones de servicio (CEEES), quien les aclara que los hidrocarburos de España son de los más baratos de Europa, pero el margen de beneficios de las petroleras es mucho mayor, lo que incrementa su precio. Esto lleva a unos magníficos resultados para Repsol, Cepsa y BP, las empresas que abarcan el oligopolio de la gasolina en España.

Alfredo Hernández recuerda que cuando España ingresó en el Mercado Común en el año 1986, asume la condición de liberalizar su economía y de acabar con la situación de monopolio en el sector petrolero. No obstante, no se llevó a cabo del todo porque el comercio de la gasolina empieza y acaba en el conglomerado Campsa.

Todos los días la petrolera le indica al encargado de cada gasolinera el precio que tiene que poner. El precio al consumo varía unas décimas según la gasolinera, pero esas diferencias inapreciables solo pretenden proyectar la imagen de competencia libre. Sin embargo, el precio está fijado, como se evidenció en estas fechas:

- En 2001, el Tribunal de Competencia sancionó a Repsol y Cepsa por fijar precios.

- En el año 2009, Repsol, Cepsa y BP recibieron una multa por la misma razón.

Sin embargo, las sanciones fueron de una cuantía muy baja en comparación con sus ingresos, por lo que a las empresas de hidrocarburos no les supone prácticamente nada no cumplir las normas.

"Salvados" también contacta en el capítulo "Oligopoly: el juego de la energía" con el empresario de E. Leclerc, un supermercado francés que tiene como reclamo una gasolinera con descuentos. Su propietario, Laurent Martin, declara tener beneficios y cree que en España hace falta competencia para que el mercado se regule y se pongan límites.

Jordi Évole entrevistó a Jorge Fabra, exconsejero de la Comisión Nacional de Energía, en Madrid, en la central eléctrica de San Sebastián de los Reyes. Declaró que la Comisión Nacional de Energía no ha sido capaz de controlar el sector y regularlo. Los actores de este sistema cuentan con asesores que hacen difícil que la Comisión Nacional de Energía cumpla con su labor con éxito. Incluso estos ayudantes tienen la capacidad de mover la opinión pública, lo que afecta a las decisiones que se toman.

El sector energético está muy mal regulado, según el exconsejero, porque hay poca transparencia. El objetivo de las empresas energéticas consiste en que su voz se oiga por encima de las críticas o las alternativas y con la opacidad lo consiguen.

La Comisión Nacional de la Energía ha intentado redireccionar la situación emitiendo un informe en 2008 que alertaba sobre los precios excesivamente altos del petróleo 
y de la luz. Hicieron hincapié en la enorme brecha entre precios y costes y en el desequilibrio que producía en contra de los consumidores.

Aun así, el gobierno no hizo nada. Además, la ausencia de datos sobre los costes hacía más difícil el control. Jorge Fabra afirma que el Gobierno dejó de seguir la cuantía de los costes con el cambio de las normas en 1997, cuando se intenta liberalizar el sector y se establece al mercado como guía para determinar el precio de la energía. Esto nos llevó a una regulación ineficaz, que sufren los consumidores. El precio es mucho mayor de lo que correspondería realmente.

Sin embargo, en las noticias podemos ver que estas empresas van a la vanguardia y que se colocan en países emergentes consiguiendo increíbles resultados. El problema está en que la regulación no traslada los beneficios de la eficiencia obtenida en el sector a los consumidores. Jorge Fabra opina que es imprescindible una reforma en el sector energético para que la situación cambie, aunque a las grandes empresas del oligopolio no les interese. La energía es muy importante, ya que constituye el segundo input esencial en cualquier empresa.

Jorge Fabra opina que los actores de este oligopolio son un lobby, ya que ejercen presión e influencia en las medidas que establece el gobierno. Esto es fácil porque el mismo ministro de Industria, Energía y Turismo, José Manuel Soria, no es experto en energía porque tiene que abarcar más campos, como el de la tecnología. Por otro lado, el funcionamiento de la industria energética se ha ido complicando con intención de generar esta confusión e incomprensión, que afecta tanto a los ciudadanos como a la clase política.

Sin embargo, piensa que el Gobierno se debe a los ciudadanos y, por ello, tiene que ejercer el poder legislativo con total independencia para reformar el sistema como es necesario. Opina que habría que derogar todas las normas existentes para escribirlas de nuevo y así conseguir un sistema más sencillo y una mayor transparencia desde las empresas.

\subsubsection{Conexión de empresas energéticas y medios}

En el libro Medios de Comunicación y Cambio Climático, Rosalba Mancinas-Chávez (2013) publicó un capítulo titulado "El silencio mediático. Reflexión en torno a las razones de los medios de comunicación para no hablar del cambio climático". Dentro recopila una lista de empresas energéticas y su conexión con los diferentes medios de comunicación y grupos españoles. En la introducción, incluye una reflexión de Ramón Reig (2010), donde afirma que, la propiedad es el condicionante de las 5 p's que más influye en el comportamiento de los medios de comunicación.

Según la investigación de Ramón Reig en el año 2012, incorporada en el estudio de Rosalba Mancinas-Chávez (2013), Endesa tuvo participaciones en Antena 3 desde 1995 hasta 1998, cuando se unió con BCH en la empresa Airtel (Endesa 8,14\%, BCH 14,9\%). En esta misma empresa tenían participaciones Unión Fenosa, Cepsa y Retevisión.

En el año 2000, Iberdrola poseía el $20 \%$ de las acciones de Veo Tv, entrando en el mismo grupo que Unedisa, del grupo italiano FIAT Rizzolli Corriere de la Sera (Mancinas, 2014: 242).

Endesa participó en la puesta en marcha de la primera plataforma de televisión digital en España, Quiero TV, donde entró con un 49\%. Igualmente tuvo un $28 \%$ de acciones en AUNA, donde Unión Fenosa tenía un 17\% (Mancinas, 2014: 242). 
General Electric es una de las grandes compañías de energía del mundo que también se dedica a la producción de electrodomésticos y a la industria de armamento. El gigante estadounidense se extendió hasta el campo de los medios de comunicación cuando adquirió NBC-Comcast, una de las empresas mediáticas más grandes de los EEUU conectada con el grupo francés Vivendi, dueña de Universal. Esto implica la propiedad de parques temáticos, industria musical y bebidas alcohólicas (Mancinas-Chávez, 2014: 242).

Chase Nominees, el fondo de inversión que custodia el banco americano JP Morgan Chase, tiene presencia en casi todas las empresas españolas de energía. También es accionista de 14 de las 35 empresas del Ibex, aunque no se sienta en ningún consejo de administración. Juega el papel de accionista mayoritario en compañías como Altadis, BBVA, Endesa y Telefónica, además de ser el segundo accionista en Acciona, Iberdrola, Indra, Repsol, YPF y SCH. Ocupa el tercer lugar en Gas Natural, Inditex, Telecinco, Banco Popular y Enegas. Por lo tanto, sólo con nombrar a esta corporación nos encontramos con toda una trama de intereses económicos que influye en el sector mediático a través de BBVA, SCH y Telefónica (Mancinas-Chávez, 2014: 243). Esta última empresa se dedica al sector de las telecomunicaciones, pero también se vincula al sector de medios a través de Digital + (Reig, 2011: 285).

En Gas Natural, Repsol YPF tiene el 30,8\% de las acciones, La Caixa 30\% y Chase Nominees 5\%. Su Consejo de Administración está formado por empresas como Adeslas o Nestlé, junto con el presidente de Vocento (Abc) y el Grupo Correo del País Vasco (Mancinas-Chávez, 2014: 243).

Dentro de Repsol encontramos a Caixabank con un 12,97\%, Sacyr Vallehermoso con un $10,01 \%$, PEMEX con un $9,49 \%$, BNP Paribas con 3,32\% y BlackRock con $3,07 \%$. Por otro lado, hay un $57,22 \%$ controlado por un misterioso conjunto de grandes empresas de múltiples sectores (Mancinas-Chávez, 2014: 243).

Rosalba Mancinas-Chávez (2014: 244) en su estudio apunta que, además de todos estos vínculos de propiedad entre las empresas, hay enlaces en los miembros de los Consejos de Administración. Por ejemplo, Matías Cortés Domínguez, Consejero de Prisa desde 1977, también es miembro del Consejo de Administración de Sacyr Vallehermoso, accionista fuerte de Repsol.

\subsubsection{Carta de UNESA}

Pocos medios de comunicación comunicaron la carta que recibió José Manuel Lara por parte del presidente de la patronal de las eléctricas (UNESA), Eduardo Montes, a raíz de la emisión del programa de "Salvados" titulado "Oligopoly: el juego de la energía". Ramón Reig (2011: 42) se refiere a este fenómeno hablando del pacto no escrito de las estructuras de poder para no agredirse. Se trata de alianzas entre las grandes esferas de la empresa y de las finanzas para no dañar la imagen de elementos clave en el Poder. No obstante, algunos medios más pequeños sí que difundieron el hecho.

Según el diario digital Oro y Finanzas, la patronal eléctrica se remitió a José Manuel Lara, presidente del Grupo Atremedia, dentro del cual se encuentran Antena 3 y La Sexta. El objetivo de la llamada de atención era conseguir una "compensación" por el trato recibido en "Salvados", ya que se destapó cómo la desregulación del sector permitía una situación de oligopolio de la industria energética y cómo la sufrían los ciudadanos en la factura de la luz. 
Fórmula TV también se hizo eco de la noticia en su página web. Según esta información, Unesa pidió espacio mediático en Antena 3 para poder aclarar y analizar las críticas al sector. En concreto, reclaman entrar en el magazine de Susana Griso, "Espejo Público". La empresa quería limpiar su imagen y sabían que sería difícil bajo las preguntas de Jordi Évole.

Jordi Évole respondió de forma clara a través de su perfil de Twitter ( 22 de noviembre de 2012):

- "Se ha conocido que UNESA, la patronal de las grandes compañías eléctricas, está molesta por no haber aparecido en el último Salvados".

- "En dicho programa descartamos un total de 15 entrevistas, como hacemos habitualmente en casi todos los Salvados".

- "Algunos medios han publicado que la entrevista no se emitió. En realidad, la entrevista con UNESA nunca se llegó a grabar. Simplemente la entrevista se descartó, algo muy habitual en la producción televisiva de un programa que dura 50 minutos".

- "Muchas gracias por todas las muestras de apoyo recibidas durante el día de hoy. Vosotros sois nuestra energía".

El apoyo popular que recibió el programa fue inmenso. En la página change.org se abrió una petición ciudadana dirigida a José Manuel Lara titulada: "Apoyo para que el programa 'Salvados' siga emitiéndose sin ningún problema”. Alcanzaron las 117.118 firmas y en la página celebran la victoria de la emisión de la última temporada y su exitoso nivel de audiencia.

Además, en una entrevista en el diario Público (Calvo, 2013), Jordi Évole:

En primer lugar toda esa campaña, que quede muy claro que no partió de nosotros. Fue espontánea y a nosotros mismos nos sorprendió. Lo que a mí sí me consta es que la patronal de las eléctricas mandó una carta bastante dura contra el programa a la presidencia de nuestro grupo, dirigida directamente a José Manuel Lara Bosch. Yo esa carta sí que la he visto y no es nada amable con nosotros. A partir de esa carta hubo quien interpretó que había un intento de coartar o de condicionar el programa, y por eso se montó la que se montó. Pero fuimos espectadores de la movida, nada más. Por cierto, la cadena salió en defensa nuestra. Así que bienvenido sea.

Como vemos, Jordi Évole no fue condicionado por los intereses económicos de las grandes empresas, lo que le permitió mantenerse firme en el rigor periodístico para conseguir una información actual, veraz y de calidad e interés para la ciudadanía. Además, el periodista no sufrió repercusiones al respecto de las quejas de UNESA.

\section{3. "Pobreza energética - Pobreza invisible"}

El 16 de febrero de 2014 "Salvados" emite el episodio "La pobreza Energética - la pobreza invisible", dentro de la décima temporada. En esta ocasión se le concede a Eduardo Montes, presidente de UNESA (que engloba Iberdrola, Endesa, Fenosa, Eon España y EPD), unos minutos para explicar la factura de la luz, como había reclamado, aunque en otro medio y en otro tipo de programa.

Al igual que en el primer programa dedicado a la energía, analizaron la factura de la luz y los impuestos y peajes que contiene. La empresa se refiere a los costes, que son más de la mitad, como "ajenos", pero no sería el calificativo más acertado. Es 
decir, Eduardo Montes se apoya en que estos peajes vienen de las diversas políticas energéticas que condicionan su actividad, como las ambientales, fiscales, territoriales y sociales. Explica que con estos impuestos cubre los costes que les obligan a pagar. "Si la política fuera otra, esos costes desaparecerían", explica Eduardo Montes. Sin embargo, todo el dinero recaudado se queda en las cuentas de la empresa para ampararla ante los costes, reduciendo así el gasto de producción para las identidades del Grupo Unesa, pero afectando a los ciudadanos, que quedan desprotegidos ante estos desorbitados precios. Por lo tanto, ante la situación de pobreza energética que vivimos en el país, Unesa ha utilizado la palabra "ajeno" para eximirse de la responsabilidad social de facilitar el acceso de un bien tan necesario como es la energía.

En cuanto a ello, Jordi Évole cita a Jorge Fabra, el exconsejero de la Comisión Nacional de Energía que apareció en el programa "Oligopoly: el juego de la energía":

La Comisión Nacional de la energía dejó de hacer un seguimiento de los costes de la energía con el cambio de las normas de 1997, cuando se intenta liberalizar el sector. Entonces, se estableció que quien fijaría los precios sería el mercado y se abandonó el seguimiento de los costes.

El equipo de "Salvados" le pregunta a Eduardo Montes porqué cada vez pagamos más de factura de la luz y, sin embargo, no se reduce el déficit tarifario. El presidente de la patronal de las eléctricas responde que los intereses que se han ido pagando en estos años siempre han sido inferiores a los que se deben.

Según Jorge Fabra, el colectivo más vulnerable queda desprotegido ante la desregulación del sistema. En nuestro modo de vida actual es un producto de primera necesidad, que se le está negando a numerosas familias en el país debido a que no pueden asumir el precio de la luz, tan elevado por la desregulación. No obstante, Eduardo Montes no entiende que los costes deban ser vigilados en una economía de libre mercado "porque el sistema no funciona así". Explica que ningún otro producto se examina de esta forma y que la electricidad no es un bien diferente.

Entonces, Jordi Évole enciende la pantalla de su iPad para poner en contacto a Eduardo Montes con la gente que sufre este descontrol del sistema energético. Además, también le enseña declaraciones de Cote Romero, coordinadora de la Plataforma por un Nuevo Modelo Energético. Explicó que el poder político debería solucionar el problema de la pobreza energética con una buena regulación del sector, aunque reconoce que es difícil "porque desgraciadamente la política energética está secuestrada por los intereses económicos de las grandes corporaciones". "El aumento del precio de la electricidad está en las manos de las grandes eléctricas", aclaró Cote Romero.

En respuesta, Eduardo Montes niega que la naturaleza de la pobreza sea energética. Además, explica que ellos están dispuestos a apoyar al Estado, pero las compañías no pueden hacerse cargo de su responsabilidad, que es solucionar la situación de malestar social.

Jordi Évole le recordó la petición por Ley del Estado en 2009 para que las compañías eléctricas se hicieran cargo de los bonos sociales, con la que Eduardo Montes no está de acuerdo. Piensa que el Estado se está eximiendo de su responsabilidad y que "no tiene sentido" que sus cinco compañías privadas lo suplanten.

Jordi Évole encauza el diálogo con calma y pericia hacia la conclusión, donde se comprueba que los intereses económicos se adentran hasta la política y que, con ello, se especula en el mercado con un bien tan necesario como es la electricidad. 
La situación de la especulación de la energía se repite en el negocio de la información, donde multitud de intereses económicos se filtran en los medios de comunicación a través de la propiedad o de los miembros de su Consejo de Administración. En este caso, el excesivo ánimo de lucro anula la función de los medios de comunicación como servicio público para garantizar el derecho a una información de calidad, útil y veraz.

En resumen, la desregulación del sistema permite que se comercie con nuestros derechos a una vida digna (con electricidad) y a recibir información veraz, recogidos en la Constitución Española vigente. La política no puede garantizar estos derechos ni amparar a los ciudadanos en ambos casos porque sobre ella impera la lógica de mercado, ya que las grandes empresas ejercen de lobby sobre los dirigentes del Estado.

\subsection{Comunicación alternativa o excepción}

Ante la situación actual de los medios de comunicación, deberíamos preguntarnos si sería conveniente una comunicación alternativa, es decir, una forma diferente de ejercer el periodismo, de carácter voluntario y que presente un mensaje para nada homogéneo (Reig, 2011).

Sin embargo, Ramón Reig (2011: 298) en su planteamiento deja a un lado la radicalidad del término comunicación alternativa y aconseja a las empresas mediáticas de mercado que traten de seguir una rutina de trabajo más rigurosa, que los periodistas tengan mejores condiciones de trabajo y que los propietarios, los accionistas o miembros del Consejo de Administración no se adueñen del medio de comunicación.

Por lo tanto, hemos de buscar una comunicación que trabaje de una forma más independiente, pero sin llegar a convertirse en una fórmula alternativa porque se saldría de la estructura misma y necesitamos que los cambios se apliquen desde dentro de ella para conseguir un periodismo más comprometido y profesional.

Si aplicamos estas reflexiones a "Salvados", Aurora Labio (2014) por su parte no cree que constituya una comunicación alternativa como tal porque se integra dentro de la estructura mediática y cumple con una demanda de público. Es cierto que se diferencia de los demás espacios televisivos, ya que trata temas variados en profundidad de una forma especial, cumpliendo siempre con ciertos estándares de calidad, pero eso no conlleva que se salga del sistema.

Sí piensa que se puede considerar una excepción dentro de la Estructura de la Información, pero sin llegar a ser un elemento herético porque no altera la organización de Atresmedia y se integra perfectamente en el grupo (Labio, 2014).

Aurora Labio (2006: 171) separa entre "periodistas obedientes" y "periodistas que pelean en la contra". Las excepciones, los profesionales más fieles al Código Deontológico de la Profesión Periodística, han dejado importantes muestras de trabajo bien hecho, como "Salvados". Los define como aquellos periodistas que asumen con responsabilidad, precisión e imparcialidad su papel de informar al público, "fruto de su reflexión personal y de la consideración que tienen sobre lo que significa ser periodista" (2006: 171).

Ramón Reig (2014) coincide con Aurora Labio en que sería más afortunado referirnos a "Salvados" como una excepción que confirma la regla dentro del sistema. Opina que el programa no constituye un elemento herético, sino uno puntualmente transgresor por salirse varias veces del guión, sembrando el desconcierto en la estructura de poder. Es decir, ha habido momentos concretos en los que 'Salvados' 
nos ha sorprendido, como el programa "Oligopoly: el juego de la energía", cuando tocó uno de los grandes brazos de poder, las industrias eléctricas. Este micro-caso de periodismo herético revolucionó la estructura y contribuyó a que la gente tomara conciencia crítica. Sin embargo, 'Salvados' no podía mantener esta línea contestataria y dejó de cuestionar las bases de la estructura del poder para que "las cosas se descafeinasen un poco". Y es que "aquí grandes torres han caído, como José Ma García o Pedro J. Ramírez”, explica Ramón Reig (2014).

El estilo propio de "Salvados" se distingue de los demás porque hace pensar más profundamente acerca de las causas de los problemas. Además, muestra cómo funcionan actividades como la justicia, los bancos, la política o el periodismo, "cosas que sabemos que están ahí, pero sin ningún fundamento... hasta que Jordi Évole nos lo enseña", simplifica Ramón Reig (2014).

Por otro lado, afirma que Atresmedia utiliza "Salvados" para autolegitimarse y poder etiquetarse como medio plural, pese a su elevado nivel de concentración. Por eso, debemos fijarnos en los porcentajes de unas voces sobre otras y ver realmente cuál es el mensaje que impera. También es cierto que mantiene el programa por la fidelidad del segmento de público al que se dirige (Reig, 2014).

\section{Conclusiones}

Al observar el panorama mediático español vemos que no existen empresas puramente comunicacionales-periodísticas y que la concentración horizontal y vertical es una de las características habituales en este sector, como en los demás. Los grupos de comunicación utilizan la información para el beneficio propio de las empresas que componen el accionariado y la cúpula de la directiva controla desde arriba que el mensaje sea uniforme y homogéneo. Los grupos de comunicación también atentan contra el pluralismo a través del máximo nivel de concentración que asumen.

Sin embargo, hemos comprobado a través de un análisis práctico de "Salvados" que en varias ocasiones ha actuado bajo su propio criterio sin tener en cuenta los intereses de las grandes empresas con las que conecta la cadena dentro del conglomerado Atresmedia. En el conflicto con UNESA por la emisión de "Oligopoly: el juego de la energía", salió airoso y sin censuras pese a que Eduardo Montes, presidente de la UNESA, le escribiese al mismo José Manuel Lara, presidente de Planeta, mostrándole su desacuerdo con la información emitida. Incluso cuando se le concedió el espacio mediático que pidió para explicarse, Jordi Évole se atrevió a someterlo a examen para que la opinión pública supiera cómo funciona el negocio de la energía, es decir, dándole la espalda al beneficio común.

Podemos decir que Jordi Évole es un periodista comprometido y que asume la responsabilidad social de su profesión, ya que trabaja según las premisas del Código Deontológico para conseguir un periodismo de calidad que beneficie a la ciudadanía en materia del ejercicio del derecho a la información en pos del desarrollo de la opinión pública y de la garantía de la democracia.

Al término de la investigación y del análisis de los datos obtenidos, podemos volver a preguntarnos si "Salvados" es una alternativa de comunicación o la excepción que confirma la regla. 
"Salvados" es un programa que se comporta de forma diferente a lo normal y que destaca por su carácter crítico e innovador y la variedad de sus polémicos temas tratados en profundidad.

No obstante, no se corresponde con la definición de comunicación alternativa porque se adapta adecuadamente a la Estructura de la Información de Atresmedia y no se ciñe únicamente al tercer sector o comunitario, sino que atiende a la demanda de su propio segmento de público. La comunicación alternativa es más radical en el sentido de que se sitúa frente al discurso dominante y sirve de herramienta democratizadora, respondiendo a los intereses de las minorías que no están representadas en los medios de comunicación y dándoles un papel activo. Como vemos, éste no es el caso de "Salvados".

Tampoco se corresponde con un elemento herético porque no llega a alterar la Estructura de la Información de Atresmedia, ya que encaja bien con los demás programas y medios de comunicación que la componen, como La Razón, de muy distinto enfoque ideológico.

Es cierto que puntualmente ha realizado un periodismo transgresor, ya que varias veces se ha salido de lo establecido, como en "Oligopoly: el juego de la energía", sorprendiendo así al brazo energético de la estructura de poder. No obstante, no ha mantenido esta línea revolucionaria en todos los episodios, por lo que no se puede considerar un elemento herético.

Sí podemos afirmar que se trata de "la excepción que confirma la regla" dentro de la Estructura de la Información porque "Salvados" realiza un periodismo atrevido que beneficia al público, frente al estilo de los demás espacios televisivos, que siguen unas pautas de periodismo dócil, conformista y oficioso. "Salvados" revela lo oculto y se preocupa por llevar a cabo buenas prácticas de la profesión periodística manteniendo su propio estilo.

El conjunto de capítulos son valientes y dignos de reconocimiento por su labor periodística, ya que se mantienen en una línea contestataria que educa la conciencia crítica de la audiencia. Por lo tanto, podemos decir que "Salvados" constituye un periodismo de calidad estándar que se sale de lo habitual.

La estructura de Atresmedia mantiene "Salvados" en la parrilla porque así cubre la determinada demanda de su público target y porque no siempre toca las bases del sistema, aunque en alguna ocasión sí lo haya hecho. Además, Atresmdia utiliza a "Salvados" para autolegitimarse y para clasificarse como conglomerado plural. Esto garantiza su supervivencia, ya que le proporciona una gran audiencia y buena imagen.

\section{Referencias}

Berger, P. y Luckmann, T. (1991). La Construcción social de la realidad. Buenos Aires: Amorrortu editores.

Bonete, P. (1995). Éticas de la Información y Deontologías del Periodismo. Madrid: Tecnos.

Calvo Y. (2013). Lo que nos quiten ahora será muy complicado de reconquistar. Público. Recuperado de http://www.publico.es/477180/

lo-que-nos-quiten-ahora-sera-muy-complicado-de-reconquistar. 
Fórmula TV (2012). La patronal eléctrica Unesa levanta el hacha de guerra contra Jordi Évole por último "Salvados". Recuperado de http://www.formulatv.com/noticias/28013/ patronal-electrica-unesa-hacha-guerra-jordi-evole-ultimo-salvados/.

Gómez García, R. y Sánchez Ruiz, E. (2014). Economía Política de la Comunicación y la Cultura. Tradiciones y conceptos. Portal de la comunicación. Recuperado de http:// www.portalcomunicacion.com/lecciones_det.asp?id=62.

Gómez, R. (2009). El Gobierno propicia la fusión de las televisiones privadas. El País. Recuperado de http://elpais.com/diario/2009/02/21/sociedad/1235170803_850215.html.

Gómez, Rosario G y Gallo, Isabel (2011). Antena 3absorbe a La Sexta". El País. Recuperado de http://sociedad.elpais.com/sociedad/2011/12/14/actualidad/1323858005_357878. html.

Labio, A. (2006). Comunicación, periodismo y control informativo. Barcelona: Anthropos.

Las Partículas Elementales (2012). Desinformación y rumorología en las redes sociales: el caso "Salvados" vs Unesa. Recuperado de http://www.mcshuibhne.com/2012/11/29/ desinformacion-y-rumorologia-en-las-redes-sociales-el-caso-salvados-vs-unesa/.

Libertad Digital (2013). Lara: 'quiero que La Sexta sea una cadena respetuosa con la derecha'. Recuperado de http://www.libertaddigital.com/espana/2013-08-21/laraquiero-que-la-sexta-sea-una-cadena-respetuosa-con-la-derechatodavia-no-loes-1276497685/.

Mancinas, R., Zurbano, B., Domínguez, S. (2011). La segmentación del mercado como estrategia de venta en España: el caso del diario Público. Revista Política de las Tecnologías de la Información y de la Comunicación, v. XIII, n² 2, mayo-agosto. Recuperado de http://www.seer.ufs.br/index.php/eptic/article/view/121/85.

Mancinas-Chávez, R. (2013). El silencio mediático. Reflexión en torno a las razones de los medios de comunicación para no hablar de cambio climático. En Fernández Reyes, R. (Dir.), Mancinas Chávez, R. (coord.), Medios de comunicación y Cambio Climático. Sevilla: Fenix Editora.

Reig, R. (1995). El control de la comunicación de masas: bases estructurales y psicosociales. Madrid: Libertarias/Prodhufi.

Reig, R. (2010). La telaraña mediática. Zamora: Comunicación Social.

Reig, R. (2011). Los dueños del periodismo. Barcelona: Gedisa.

Serrano, P. (2010). Traficantes de Información. Madrid: Foca.

Urías, J. (2003). Lecciones de Derecho de la Información. Madrid: Tecnos.

Vacas, R. (2010). El perfil de la audiencia Cuatro y La Sexta (2005-2008).

\subsection{Documentos audiovisuales}

Salvados (2012). "Oligopoly: el juego de la energía". La Sexta, 18 de noviembre.

Salvados (2013). "Desmontando Salvados". La Sexta, 24 de febrero.

Salvados (2014a). "Pobreza energética - Pobreza invisible". La Sexta, 16 de febrero.

Salvados (2014b). “Operación Palace 23F”. La Sexta, 23 de febrero. 


\subsection{Fuentes orales}

Labio, A. (2014). Entrevista personal realizada por Elizabeth Galán, el 22 de mayo de 2014.

Reig, R. (2014). Entrevista personal realizada por Elizabeth Galán, el 2 de junio de 2014. 